Supporting Information

\title{
Thermoresponsive Supramolecular Assemblies from Dendronized Amphiphiles to Form Fluorescent Spheres with Tunable Chirality
}

Yanjun Liu,,${ }^{\# 1}$ Yuexin Cao, ${ }^{\#, 1}$ Xiacong Zhang, ${ }^{\#, 1}$ Yaodong Lin, ${ }^{1}$ Wen Li, ${ }^{* 1}$ Baris Demir, ${ }^{* 2}$ Debra J. Searles, ${ }^{2,3}$ Andrew K. Whittaker, ${ }^{2,4}$ and Afang Zhang ${ }^{* 1}$

1 International Joint Laboratory of Biomimetic and Smart Polymers

School of Materials Science and Engineering, Shanghai University, 99 Shangda Road, Mailbox 152, Shanghai 20444, China

2 Australian Institute for Bioengineering and Nanotechnology (AIBN)

The University of Queensland, Brisbane, Qld 4072, Australia

3 School of Chemistry and Molecular Biosciences

The University of Queensland, Brisbane, Qld 4072, Australia

4 ARC Centre of Excellence in Convergent Bio-Nano Science and Technology

The University of Queensland, Brisbane Qld 4072, Australia 


\section{Table of Contents}

Scheme S1. Synthetic procedure for TPE-GA-G1 and TPE-GA(r)-G1 ........................................ 3

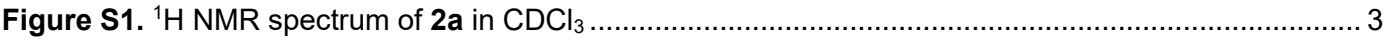

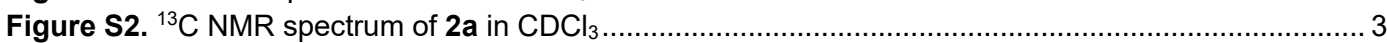

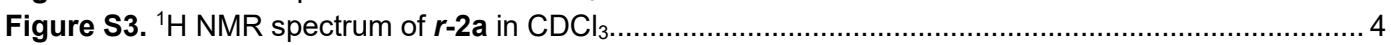

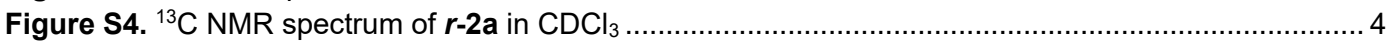

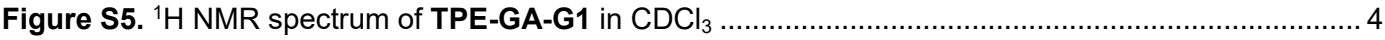

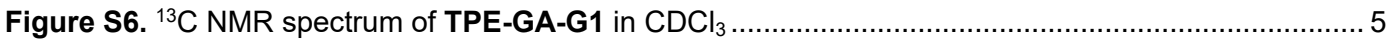

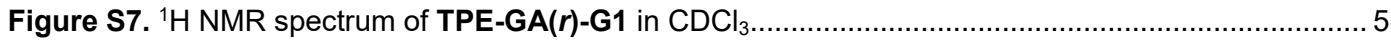

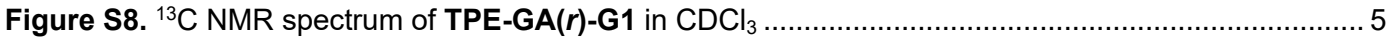

Figure S9. ESI-MS (pos. mode, $\mathrm{MeOH}$ ) of 2a

Figure S10. ESI-MS (pos. mode, $\mathrm{MeOH}$ ) of $\boldsymbol{r}$-2a ...................................................................... 6

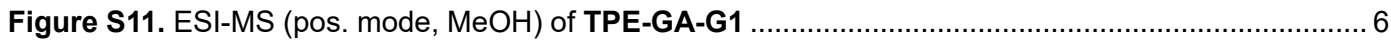

Figure S12. ESI-MS (pos. mode, MeOH) of TPE-GA(r)-G1 ...................................................... 6

Figure S13. Plot of fluorescent emission at $479 \mathrm{~nm}$ of TPE-GA-G1 versus its log C: (a) TPE-GA-G1; (b) TPE-GA $(r)$-G1

Figure S14. Fluorescence (FL) spectra (a) and plots of DLS measurements (b) of TPE-GA-G1 in mixtures of THF/ $\mathrm{H}_{2} \mathrm{O}$ with different water fractions ( $\left.f_{w}\right)$. Photographs (c) of TPE-GA-G1 taken under a hand-held UV lamp $\left(\lambda_{\text {ex }}=365 \mathrm{~nm}\right)$ in $\mathrm{THF} / \mathrm{H}_{2} \mathrm{O}$ mixtures with $\mathrm{f}_{\mathrm{w}}$ from 0 to $95 \%$

Figure S15. AFM images of nanospheres on mica formed from TPE-GA-G1 in THF/ $\mathrm{H}_{2} \mathrm{O}$ mixtures with different $f_{w}$ at different temperature

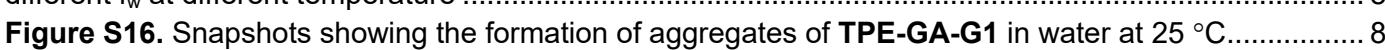

Figure S17. Snapshots showing TPE-GA-G1 in pure water, a mixture of THF and water $\left(f_{w}=90 \%\right)$ and pure THF at $25^{\circ} \mathrm{C}$

Figure S18. Snapshots showing TPE-GA-G1 in (a)-(c) pure water, (d)-(f) a mixture of THF and water $\left(f_{w}=\right.$ $90 \%$ ) and (g)-(i) pure THF at $25^{\circ} \mathrm{C}$.....

Figure S19. Molecular dynamic simulations: (a) the assembly of molecules versus their TPE sites represented in black

Figure S20. Intermolecular radial distribution functions (RDF) and coordination number (CN) plots between the oxygen atoms of the OEG moieties and carbon atom of the methyl group from alanine ................... 10

Figure S21. CD-UV spectra of TPE-GA-G1 in different solvents at room temperature.......................... 10 Figure S22. Snapshots taking at the completion of the simulations, showing the distribution of polymer (shown in vdW surface) in pure THF (shown as yellow) at two temperatures....

... 11

Figure S23. NOESY spectra of TPE-GA-G1 in mixture of THF- $d_{8} / D_{2} O$ at different water $f_{w}:(a) f_{w}=70 \%, 20$ ${ }^{\circ} \mathrm{C}$; (b) $\mathrm{f}_{\mathrm{w}}=82 \%, 20^{\circ} \mathrm{C}$; (c) $\mathrm{f}_{\mathrm{w}}=84 \%, 20^{\circ} \mathrm{C}$; (d) $\mathrm{f}_{\mathrm{w}}=90 \%, 20^{\circ} \mathrm{C}$; and $(\mathrm{e}) \mathrm{f}_{\mathrm{w}}=90 \%, 36^{\circ} \mathrm{C} \ldots \ldots \ldots \ldots \ldots \ldots . \ldots \ldots \ldots \ldots$

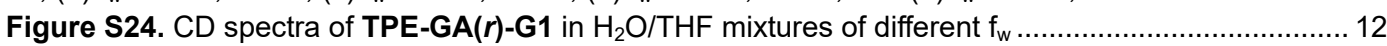
Figure S25. CD spectra of TPE-GA-G1 in $\mathrm{H}_{2} \mathrm{O} / \mathrm{MeOH}(\mathrm{a})$ and $\mathrm{H}_{2} \mathrm{O}$ / acetonitrile (b) of different $\mathrm{f}_{\mathrm{w}} \mathrm{s}$, as well as TPE-GA(r)-G1 in $\mathrm{H}_{2} \mathrm{O} / \mathrm{MeOH}(\mathrm{c})$ and $\mathrm{H}_{2} \mathrm{O}$ / acetonitrile (d) of different $\mathrm{f}_{\mathrm{w}} \mathrm{s}$...................................... 13 Figure S26. Plots of transmittance versus temperature for TPE-GA( $r)$-G1 ....................................... 13 Figure S27. Fluorescence (FL) spectra of TPE-GA-G1 in $\mathrm{H}_{2} \mathrm{O} / \mathrm{THF}$ excited at $312 \mathrm{~nm}$ with increase (a) and decrease (b) of temperatures, as well as the CD spectra with increasing (c) and decrease (d) of temperature. $\mathrm{f}_{\mathrm{w}}=90 \%$......

14

Figure S28. Fluorescence (FL) spectra of TPE-GA-G1 in $\mathrm{H}_{2} \mathrm{O} / \mathrm{THF}$ excited at $312 \mathrm{~nm}$ with increase (a) and decrease (b) of temperatures, as well as the CD spectra with increasing (c) and decrease (d) of temperature. $f_{w}=95 \%$.

Figure S29. Cotton effect at $287 \mathrm{~nm}$ of TPE-GA-G1 in mixture of $\mathrm{H}_{2} \mathrm{O} / \mathrm{THF}$ with different heating rate ... 15 Figure S30. ${ }^{1} \mathrm{H}$ NMR spectra of TPE-GA-G1 in mixture of THF- $d_{8} / D_{2} \mathrm{O}$ at different temperatures: $(a) f_{w}=$ $84 \%,(b) f_{w}=95 \%$ 


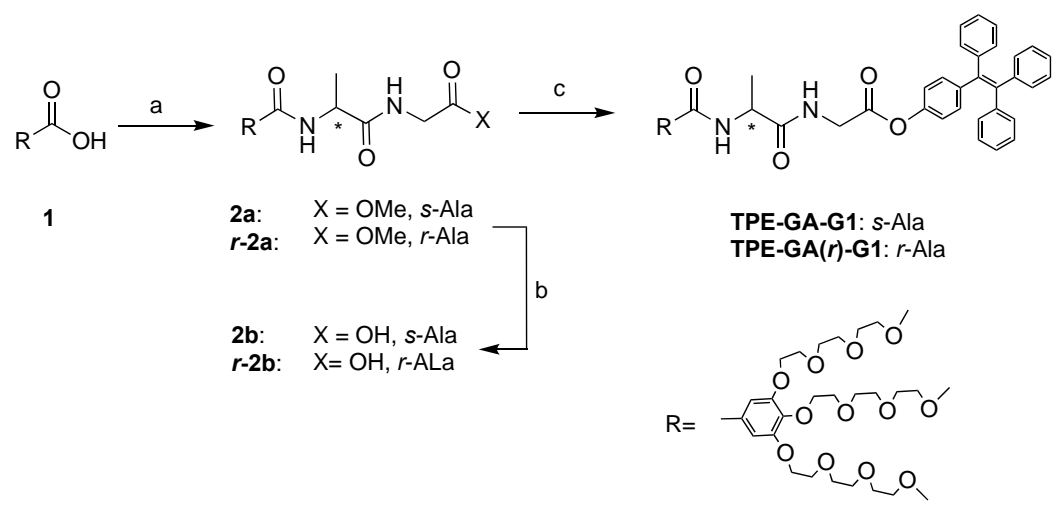

Scheme S1. Synthetic procedure for TPE-GA-G1 and TPE-GA(r)-G1. Reagents and conditions: a) $\mathrm{CH}_{2} \mathrm{Cl}_{2}, \mathrm{H}-\mathrm{L}-\mathrm{Ala}$-Gly-OMe-TFA or H-D-Ala-Gly-OMe-TFA, HOBt, DiPEA, EDC. HCl, 0-25 ${ }^{\circ} \mathrm{C}$, overnight (55\%); b) MeOH, $\mathrm{H}_{2} \mathrm{O}$, LiOH· $\mathrm{H}_{2} \mathrm{O}, 25^{\circ} \mathrm{C}, 3 \mathrm{~h}(\mathbf{2 a :} 87 \% ; r$-2a: $61 \%$ ); c) $\mathrm{CH}_{2} \mathrm{Cl}_{2}$, TPE-OH, DMAP, EDC. HCl, 0-25 ${ }^{\circ} \mathrm{C}$, overnight (TPE-GA-G1: 53\%; TPE-GA(r)-G1: 64\%). Abbreviations: DMAP = 4dimethylaminopyridine; $\mathrm{EDC} \cdot \mathrm{HCl}=1$-(3-dimethylaminopropyl)-3-ethylcarbodiimide hydrochloride; $\mathrm{HOBt}=$ 1-hydroxy-1 $\mathrm{H}$-benzotriazole; DiPEA = diisopropylethylamine; THF = tetrahydrofuran; TPE-OH = 4-(1, 2, 2-triphenylvinyl) phenol.

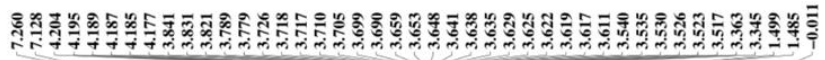

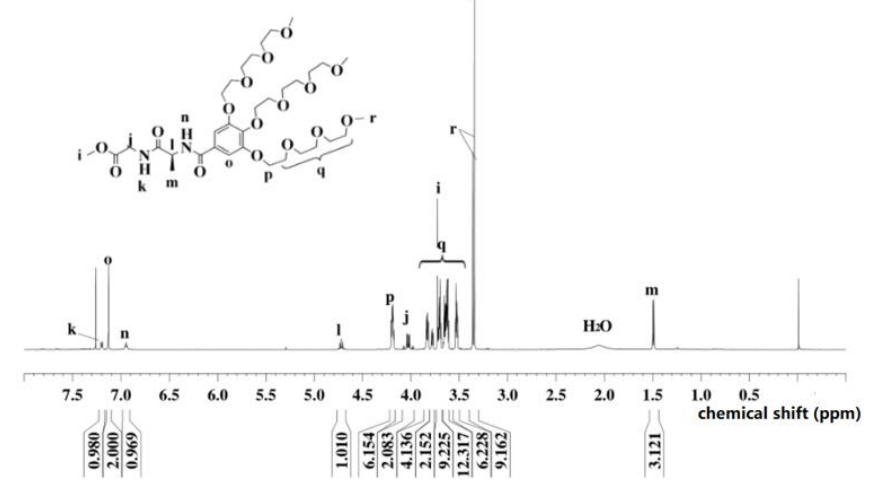

Figure S1. ${ }^{1} \mathrm{H}$ NMR spectrum of $2 \mathrm{a}$ in $\mathrm{CDCl}_{3}\left(25^{\circ} \mathrm{C}\right)$.
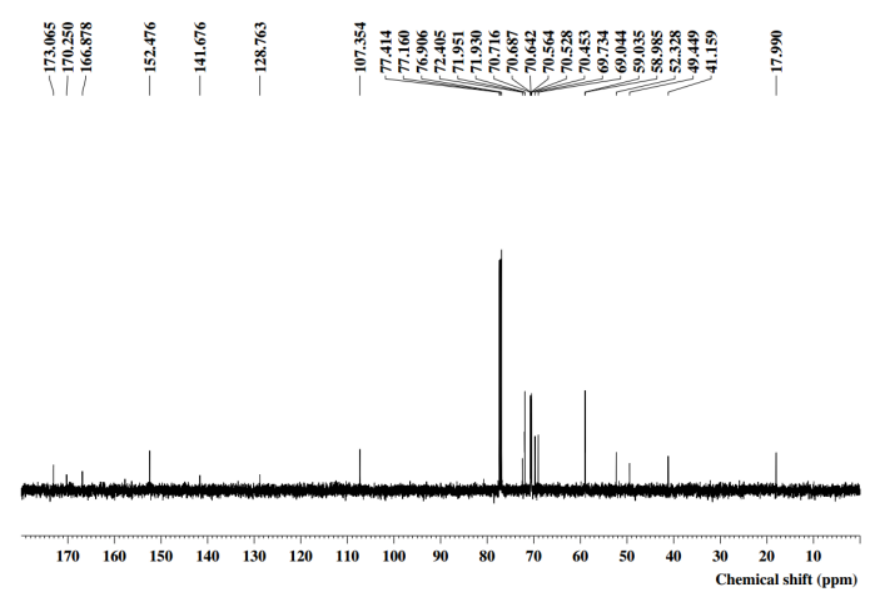

Figure S2. ${ }^{13} \mathrm{C}$ NMR spectrum of $2 \mathbf{a}$ in $\mathrm{CDCl}_{3}\left(25^{\circ} \mathrm{C}\right)$. 


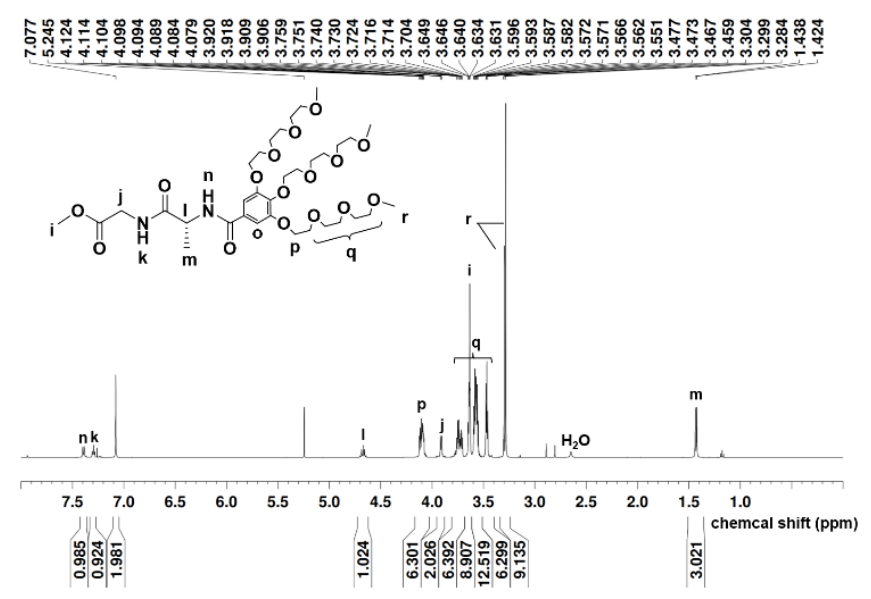

Figure S3. ${ }^{1} \mathrm{H}$ NMR spectrum of $\boldsymbol{r}$-2a in $\mathrm{CDCl}_{3}\left(25^{\circ} \mathrm{C}\right)$.

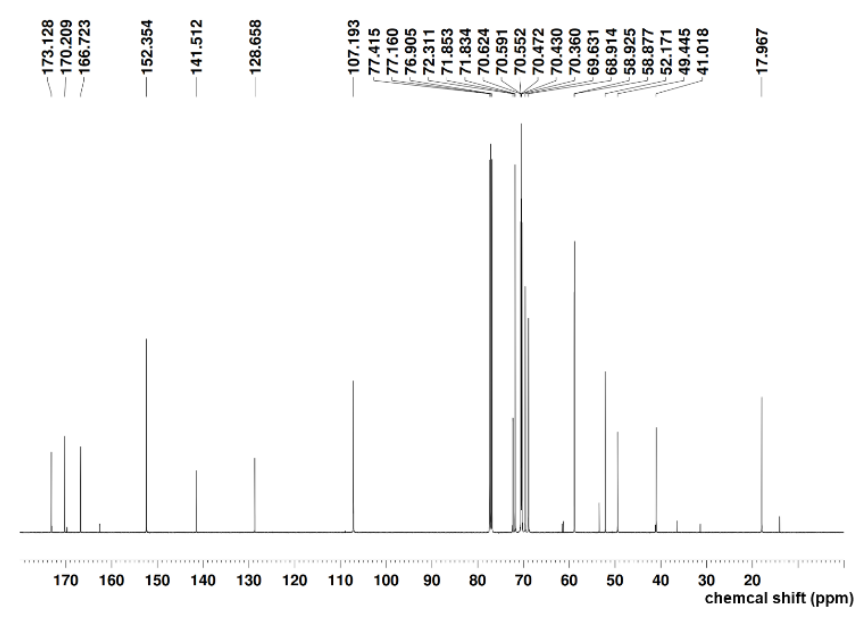

Figure S4. ${ }^{13} \mathrm{C}$ NMR spectrum of $\boldsymbol{r}$-2a in $\mathrm{CDCl}_{3}\left(25^{\circ} \mathrm{C}\right)$.

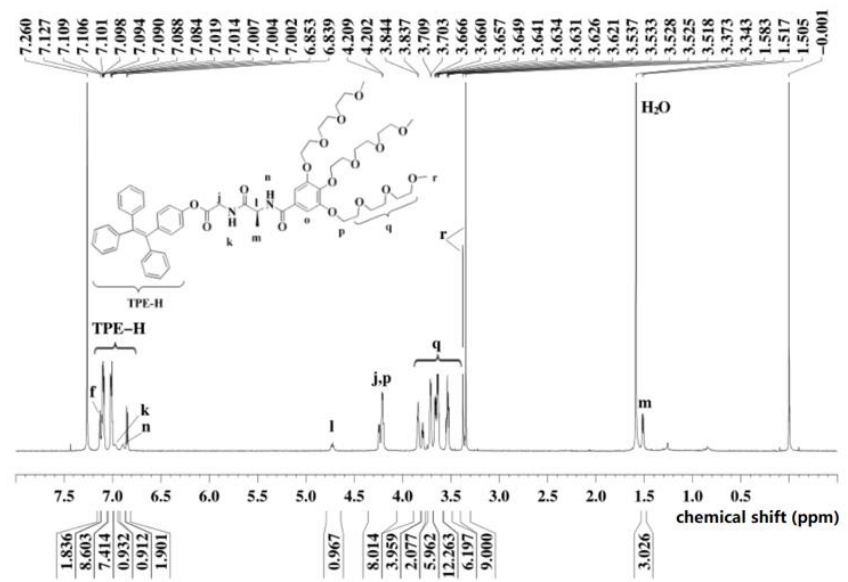

Figure S5. ${ }^{1} \mathrm{H}$ NMR spectrum of TPE-GA-G1 in $\mathrm{CDCl}_{3}\left(25^{\circ} \mathrm{C}\right)$. 


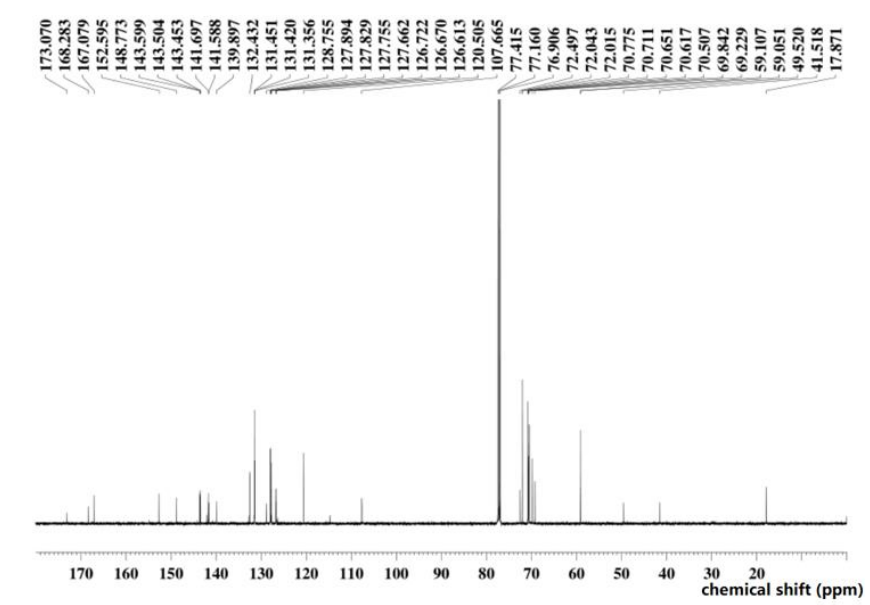

Figure S6. ${ }^{13} \mathrm{C}$ NMR spectrum of TPE-GA-G1 in $\mathrm{CDCl}_{3}\left(25^{\circ} \mathrm{C}\right)$.

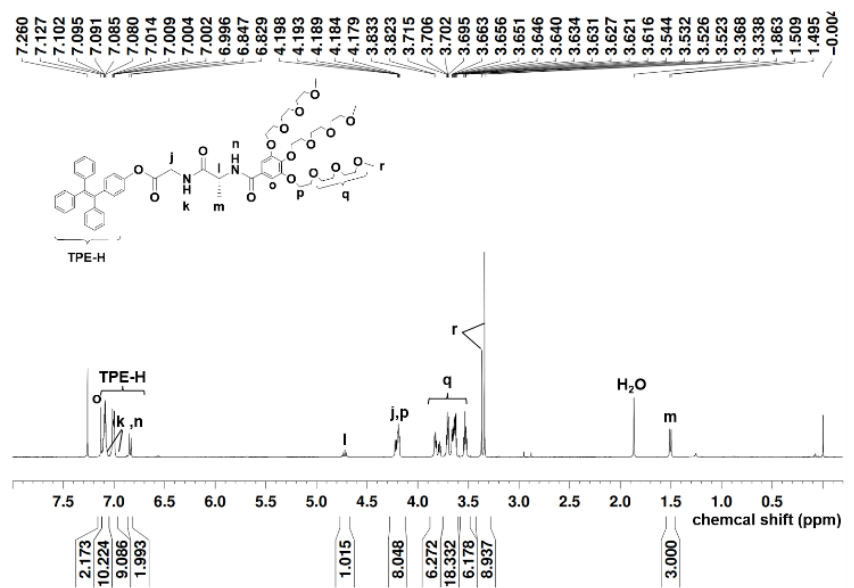

Figure S7. ${ }^{1} \mathrm{H}$ NMR spectrum of TPE-GA(r)-G1 in $\mathrm{CDCl}_{3}\left(25^{\circ} \mathrm{C}\right)$.

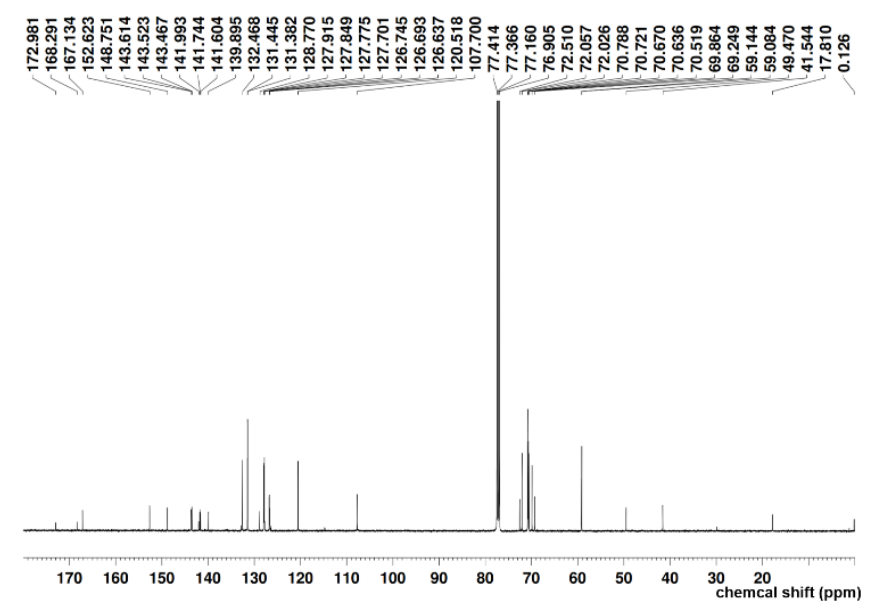

Figure S8. ${ }^{13} \mathrm{C}$ NMR spectrum of TPE-GA(r)-G1 in $\mathrm{CDCl}_{3}\left(25^{\circ} \mathrm{C}\right)$. 


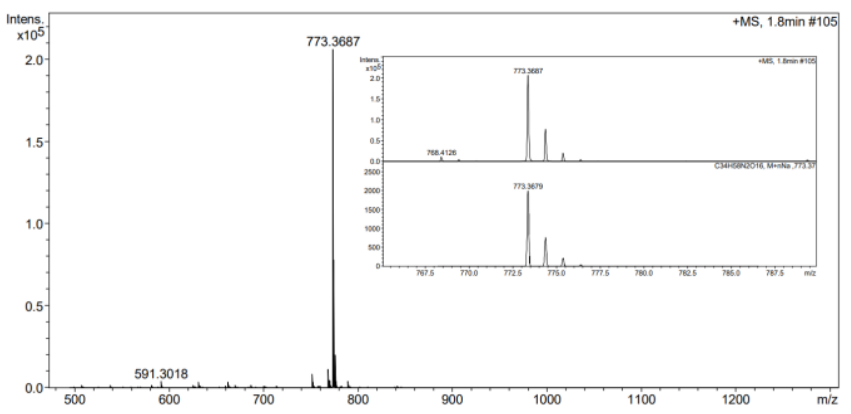

Figure S9. ESI-MS (pos. mode, $\mathrm{MeOH}$ ) of $\mathbf{2 a}$

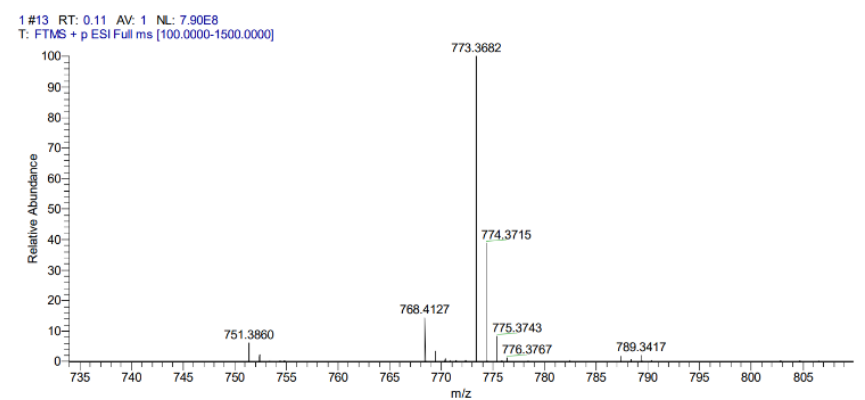

Figure S10. ESI-MS (pos. mode, MeOH) of $\boldsymbol{r}$-2a.

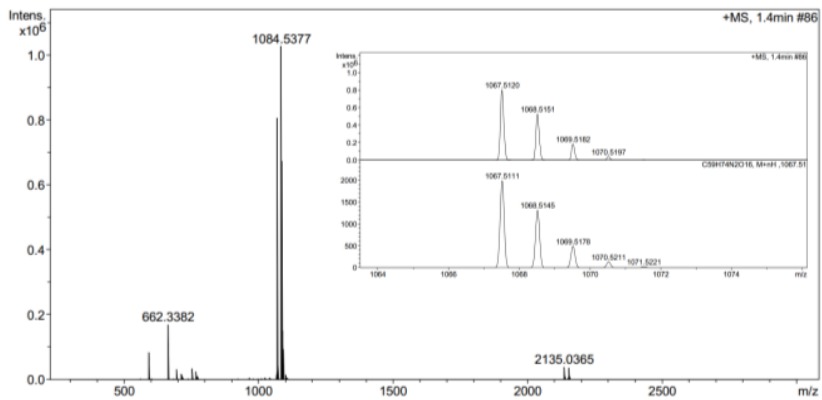

Figure S11. ESI-MS (pos. mode, MeOH) of TPE-GA-G1.

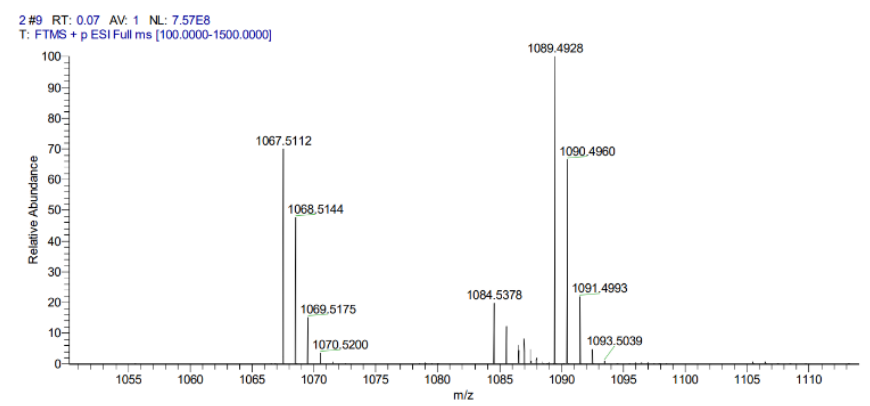

Figure S12. ESI-MS (pos. mode, MeOH) of TPE-GA(r)-G1. 

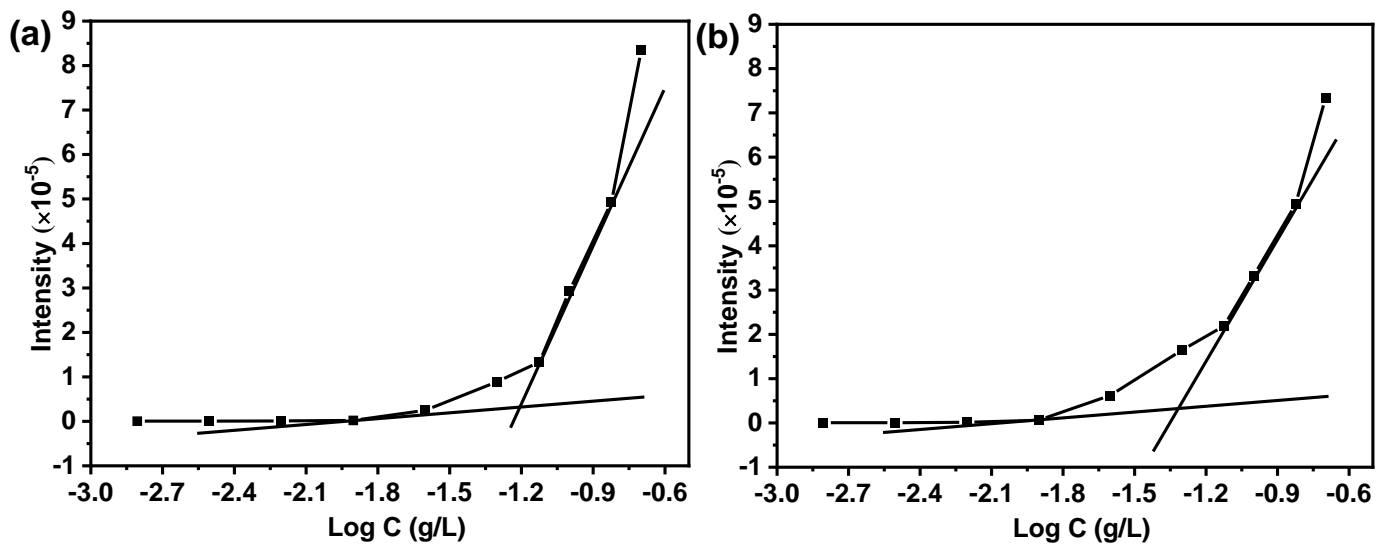

Figure S13. Plot of fluorescent emission at $479 \mathrm{~nm}$ of TPE-GA-G1 versus its log C: (a) TPE-GA-G1; (b) TPE-GA(r)-G1. T = 20 ${ }^{\circ} \mathrm{C}, \mathrm{f}_{\mathrm{w}}=$ $90 \%, \lambda_{\text {ex }}=312 \mathrm{~nm}$.
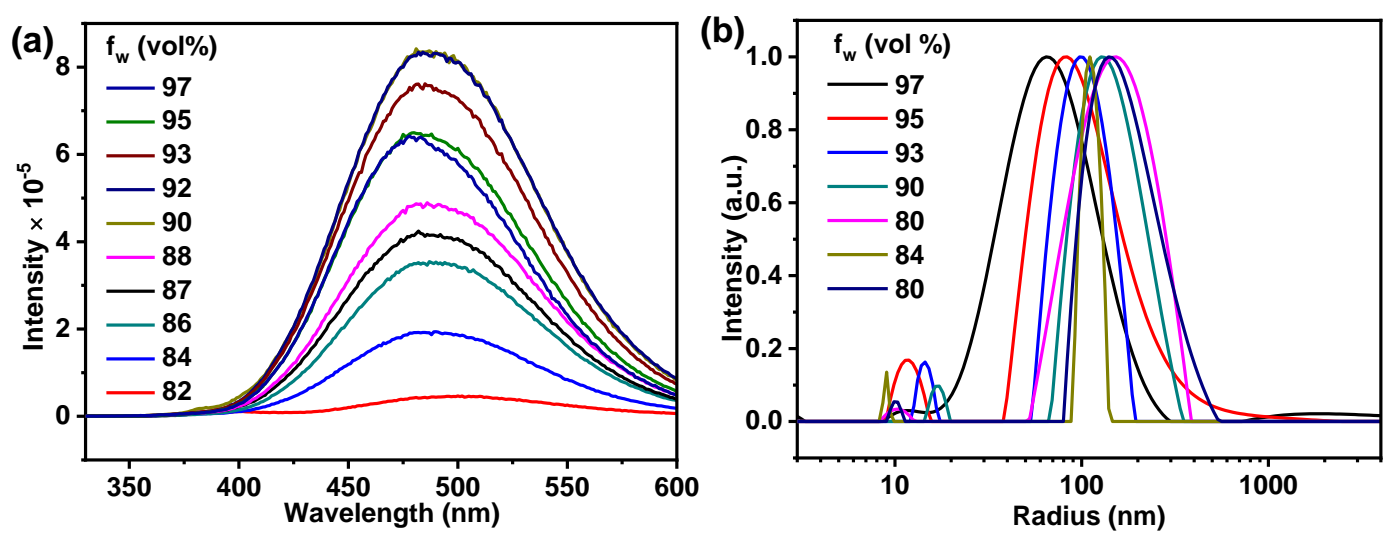

(c)

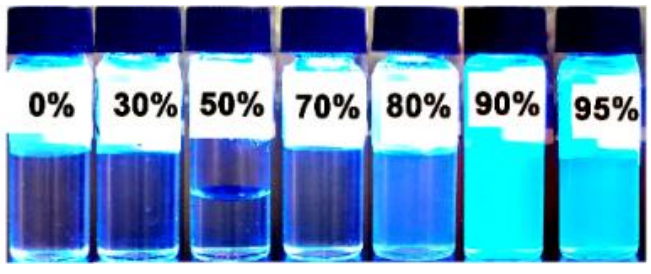

Figure S14. Fluorescence (FL) spectra (a) and plots of DLS measurements (b) of TPE-GA-G1 in mixtures of THF/ $\mathrm{H}_{2} \mathrm{O}$ with different water fractions $\left(f_{w}\right) .20^{\circ} \mathrm{C}, \lambda_{e x}=312 \mathrm{~nm}$. Photographs (c) of TPE-GA-G1 taken under a hand-held UV lamp $\left(\lambda_{\mathrm{ex}}=365 \mathrm{~nm}\right)$ in THF/ $\mathrm{H}_{2} \mathrm{O}$ mixtures with $\mathrm{f}_{\mathrm{w}}$ from 0 to $95 \%$. Sample concentration $=0.2 \mathrm{mg} \cdot \mathrm{mL}^{-1}$.
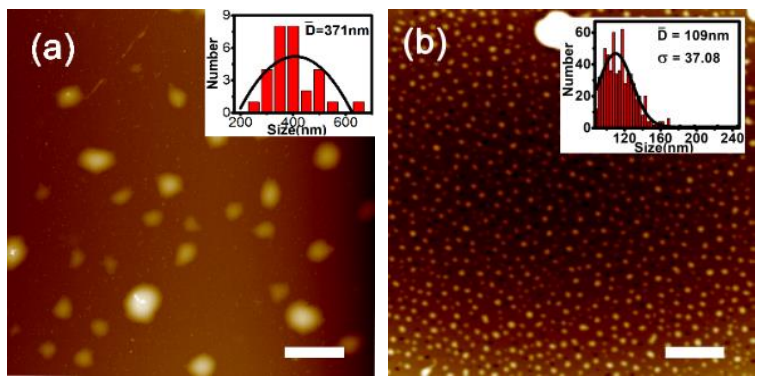

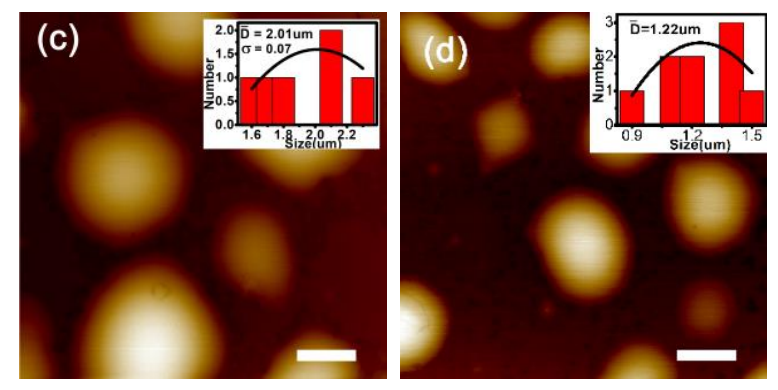

Figure S15. AFM images of nanospheres on mica formed from TPE-GA-G1 in THF/ $/ \mathrm{H}_{2} \mathrm{O}$ mixtures with different $\mathrm{f}_{\mathrm{w}}$ at different temperature. (a) $\mathrm{f}_{\mathrm{w}}=86 \%, 20^{\circ} \mathrm{C}$; (b) $\mathrm{f}_{\mathrm{w}}=95 \%, 20^{\circ} \mathrm{C}$; (c) $\mathrm{f}_{\mathrm{w}}=90 \%, 50{ }^{\circ} \mathrm{C}$, and $(\mathrm{d}) \mathrm{f}_{\mathrm{w}}=95 \%, 50{ }^{\circ} \mathrm{C}$. C $=0.2 \mathrm{mg} \cdot \mathrm{mL}^{-1}$, scale bar $=800 \mathrm{~nm}$.

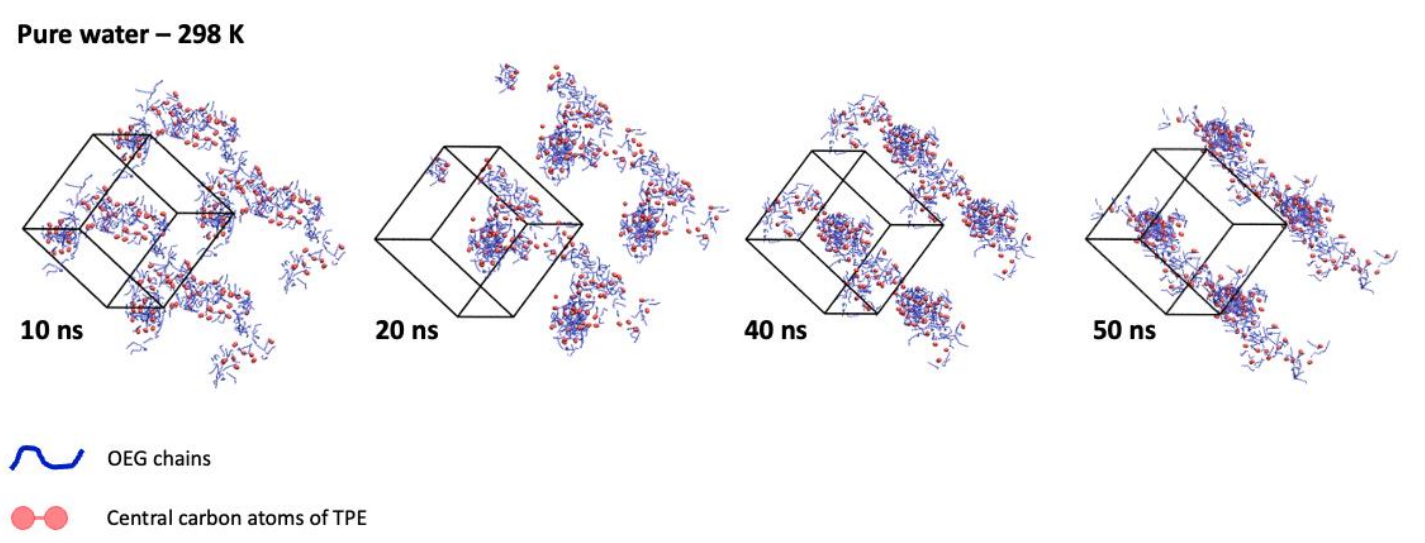

Figure S16. Snapshots showing the formation of aggregates of TPE-GA-G1 in water at $25^{\circ} \mathrm{C}$. The more hydrophilic OEG chains are shown in blue and the central carbon atoms (ethylene group) of TPE are shown as red spheres. Four periodic images of the simulation cell are shown.

Pure water $-298 \mathrm{~K}$

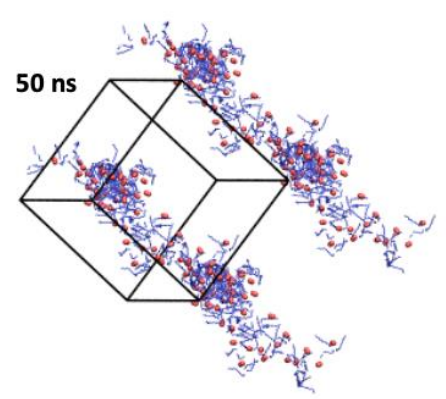

Mix $-298 \mathrm{~K}$

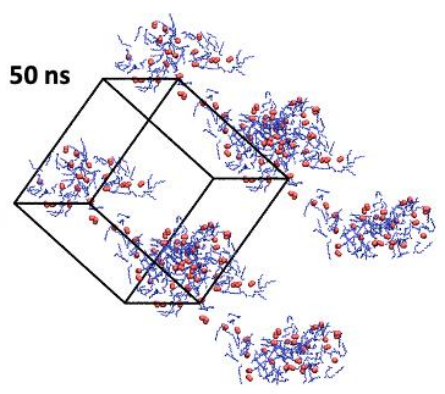

Pure THF - $298 \mathrm{~K}$

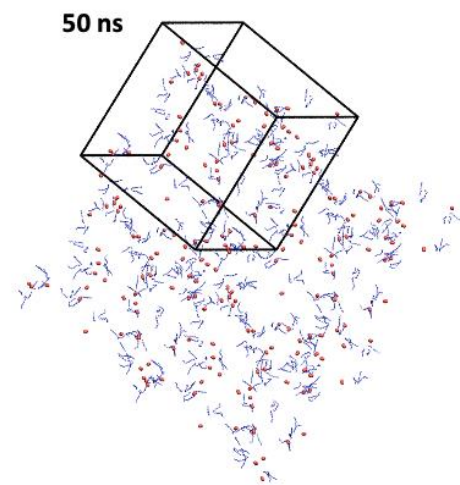

Figure S17. Snapshots showing TPE-GA-G1 in pure water, a mixture of THF and water $\left(\mathrm{f}_{w}=90 \%\right)$ and pure THF at $25^{\circ} \mathrm{C}$. The more hydrophilic OEG chains are shown in blue and the central carbon atoms of TPE are shown as red spheres. Four periodic images of the simulation cell are shown. It is evident that the polymer aggregates in the water and water-rich systems whereas it is dispersed in pure THF. The size of the aggregates is larger with $\mathrm{f}_{\mathrm{w}}=90 \%$ than with $\mathrm{f}_{\mathrm{w}}=100 \%$. 
Pure Water at $298 \mathrm{~K}$
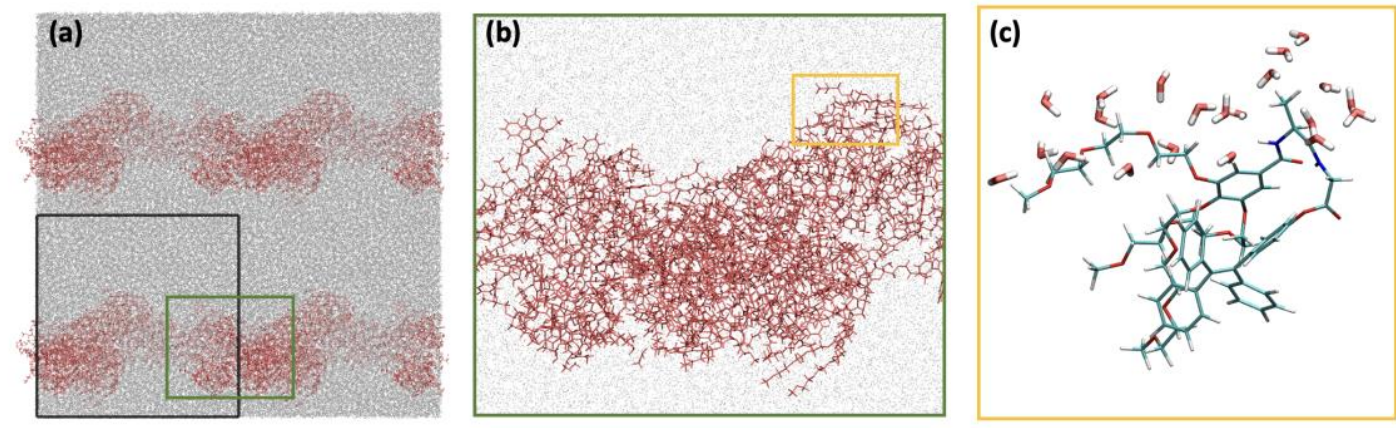

Water - THF mix at $298 \mathrm{~K}$
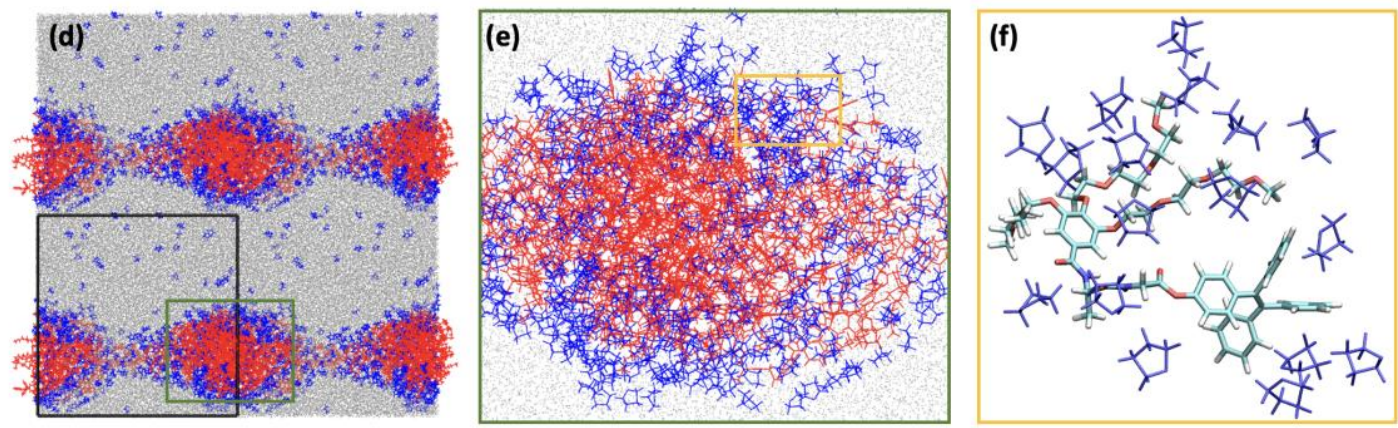

Pure THF at $298 \mathrm{~K}$
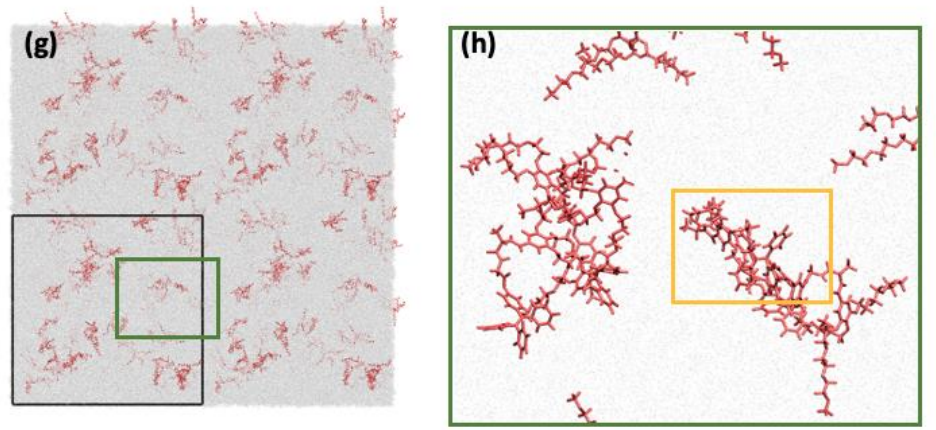

Figure S18. Snapshots showing TPE-GA-G1 in (a)-(c) pure water, (d)-(f) a mixture of THF and water $\left(\mathrm{f}_{\mathrm{w}}=90 \%\right)$ and $(\mathrm{g})-(\mathrm{i})$ pure $\mathrm{THF}$ at $25^{\circ} \mathrm{C}$. Two periodic images of the simulation cell in each direction (black squares) are shown in (a), (d) and (g). Closer images of parts of the simulation cell are shown in detail in (b), (c), (e), (f), (h) and (i). In (a), (b), (d), (e), (g) and (h), TPE-GA-G1 molecules are red, THF molecules blue and water molecules are grey. In (c), (f) and (i), water molecules have been removed, THF is blue and TPE-GAG1 is drawn as a stick model with oxygen atoms red, hydrogen atoms white, carbon atoms cyan, and nitrogen atoms blue. Note that the expanded views are zoomed in all directions, so some molecules visible in the boxes are not visible in the zoomed images. 

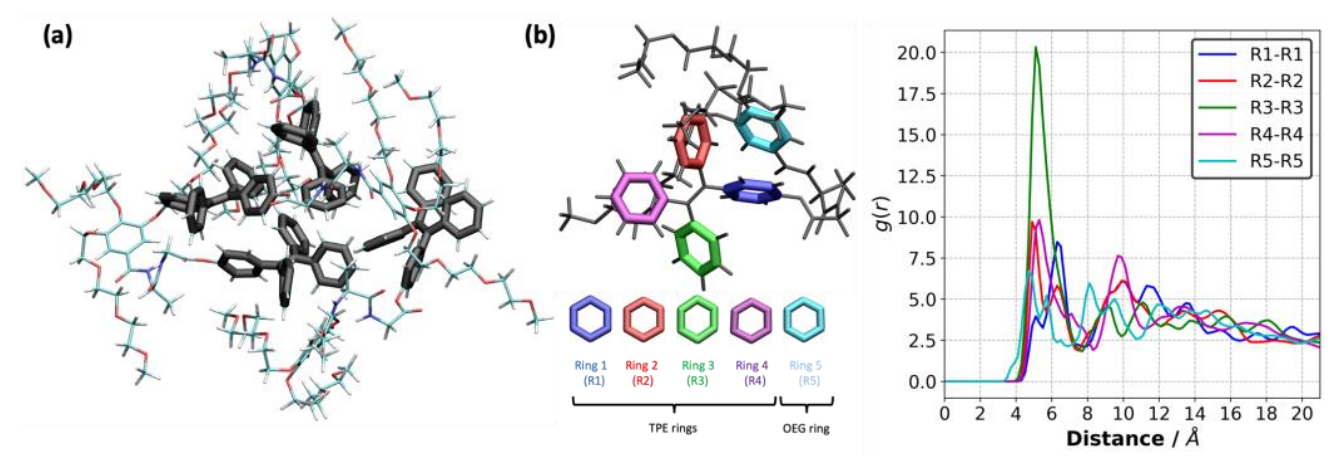

Figure S19. Molecular dynamic simulations: (a) the assembly of molecules versus their TPE sites represented in black. Water molecules are not shown for clarity; (b) The aromatic rings making up the TPE and OEG dendron, and the radial distribution function calculated between each same aromatic ring pair in pure water at $25^{\circ} \mathrm{C}$.

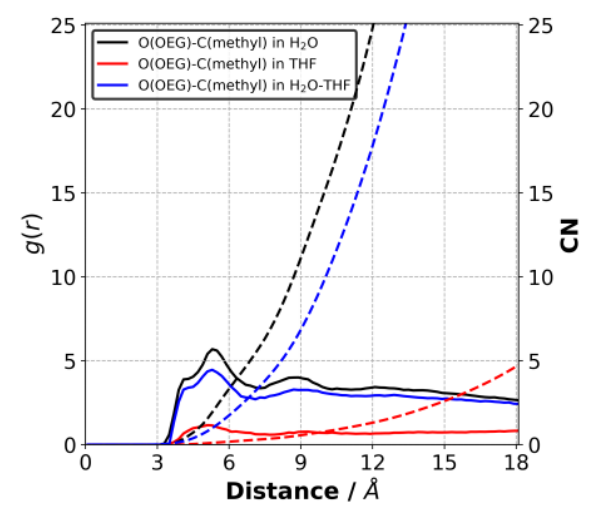

Figure S20. Intermolecular radial distribution functions (RDF) and coordination number (CN) plots between the oxygen atoms of the OEG moieties and carbon atom of the methyl group from alanine. The simulations were at $25{ }^{\circ} \mathrm{C}$, in pure water (black), $\mathrm{f}_{\mathrm{w}}=90 \%(\mathrm{blue})$ or pure THF (red).

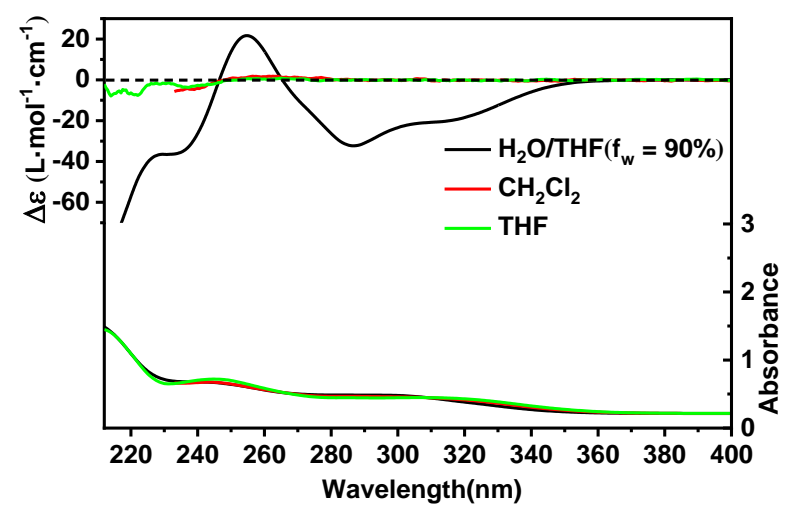

Figure S21. CD-UV spectra of TPE-GA-G1 in different solvents at room temperature. $\mathrm{c}=0.2 \mathrm{mg} \cdot \mathrm{mL}^{-1}$. 

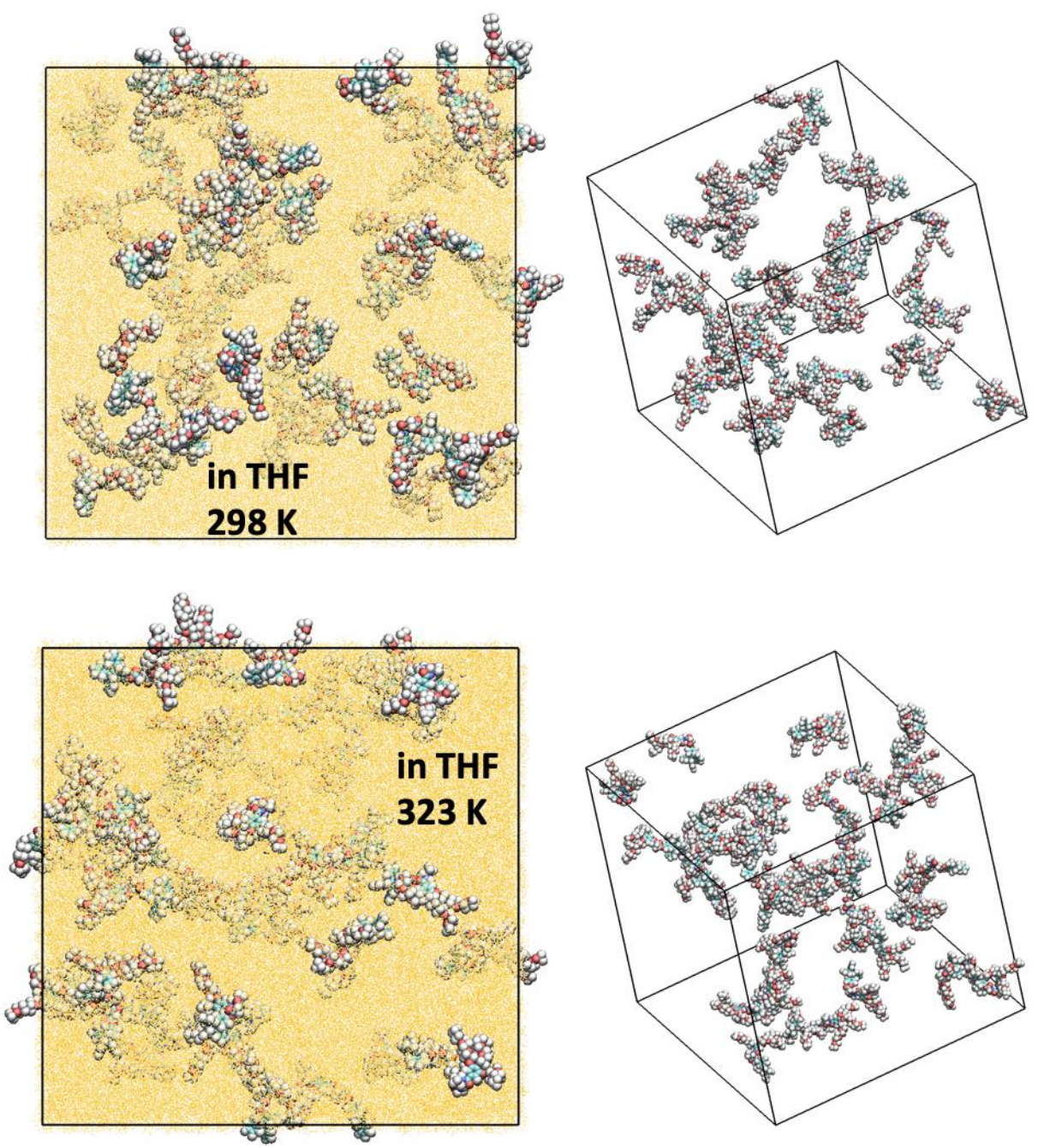

Figure S22. Snapshots taking at the completion of the simulations, showing the distribution of polymer (shown in vdW surface) in pure THF (shown as yellow) at two temperatures. Black solid lines represent simulation cell boundaries. 

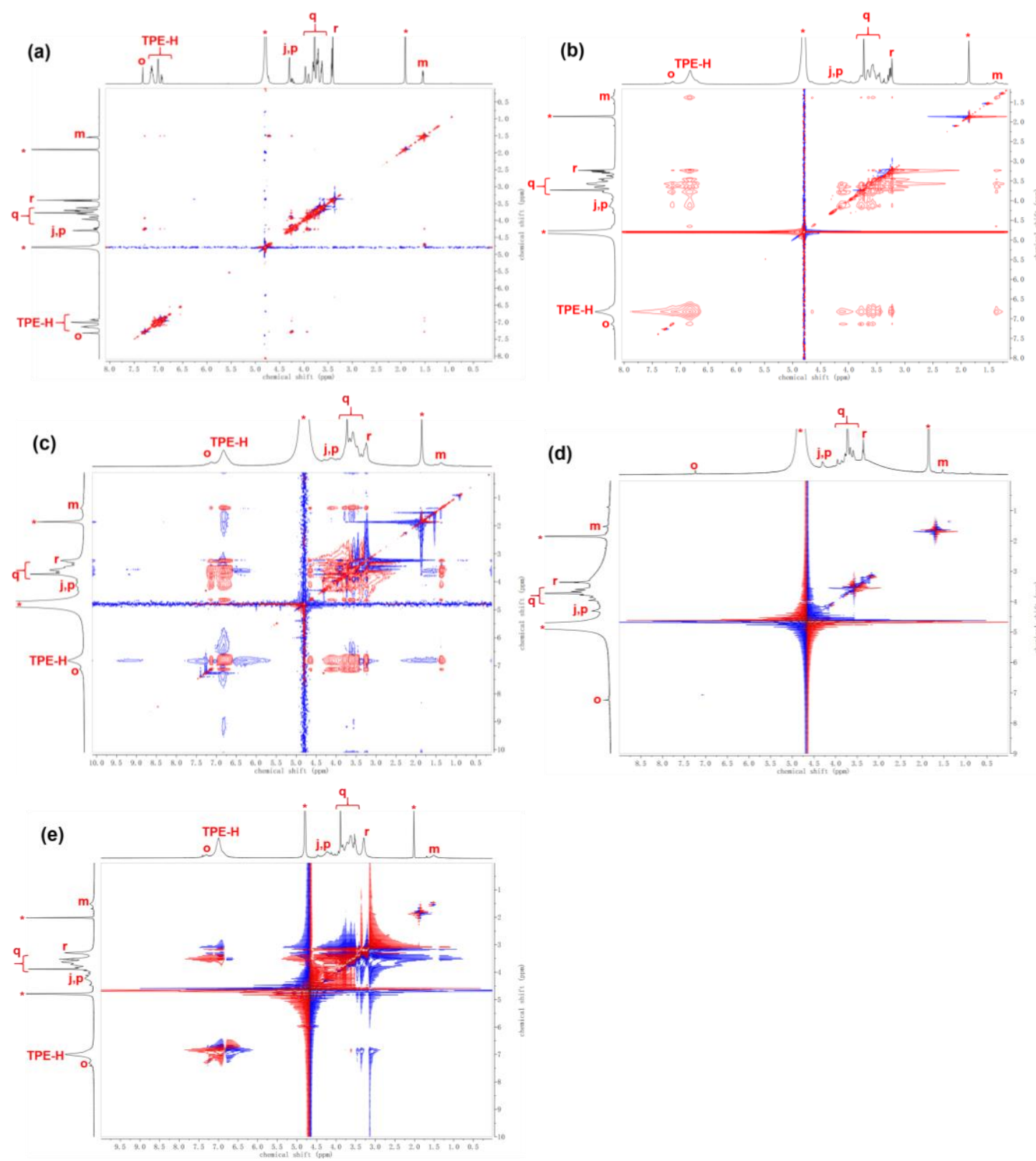

Figure S23. NOESY spectra of TPE-GA-G1 in mixture of THF- $d_{8} / D_{2} \mathrm{O}$ at different water $\mathrm{f}_{\mathrm{w}}:(\mathrm{a}) \mathrm{f}_{\mathrm{w}}=70 \%, 20{ }^{\circ} \mathrm{C} ;(\mathrm{b}) \mathrm{f}_{\mathrm{w}}=82 \%, 20{ }^{\circ} \mathrm{C} ;(\mathrm{c})$ $f_{w}=84 \%, 20^{\circ} \mathrm{C}$; (d) $f_{w}=90 \%, 20^{\circ} \mathrm{C}$; and $(e) f_{w}=90 \%, 36^{\circ} \mathrm{C} . \mathrm{c}=5.0 \mathrm{mg} \cdot \mathrm{mL}^{-1}$. For proton assignments, please refer to Figure $2 \mathrm{c}$.

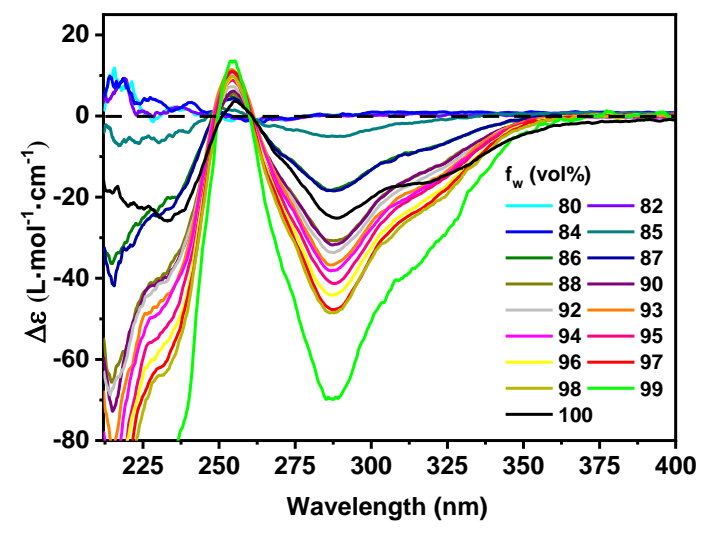

Figure S24. CD spectra of TPE-GA(r)-G1 in $\mathrm{H}_{2} \mathrm{O} / \mathrm{THF}$ mixtures of different $\mathrm{f}_{\mathrm{w}} .20^{\circ} \mathrm{C}, \mathrm{C}=0.2 \mathrm{mg} \cdot \mathrm{mL}^{-1}$. 

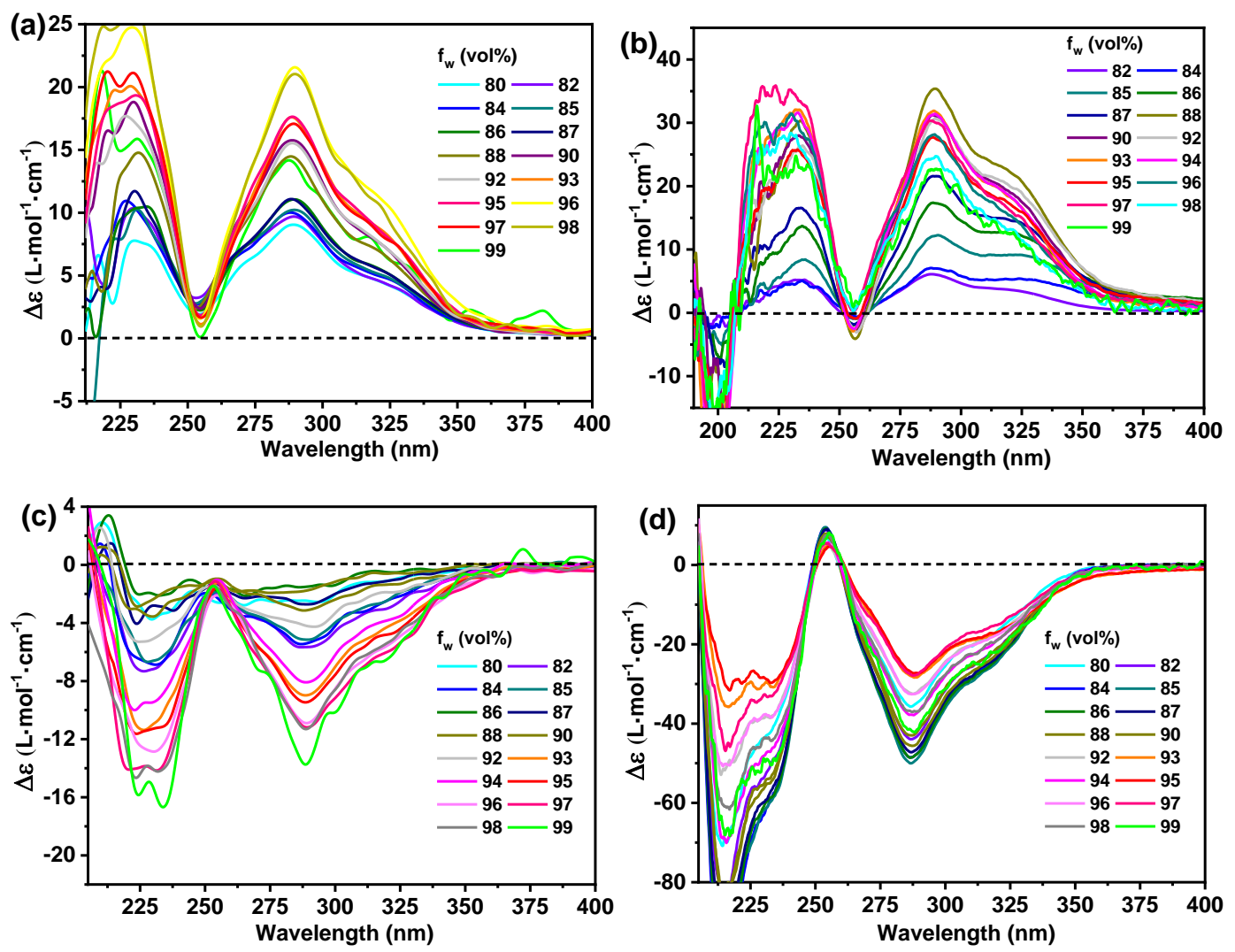

Figure S25. CD spectra of TPE-GA-G1 in $\mathrm{H}_{2} \mathrm{O} / \mathrm{MeOH}$ (a) and $\mathrm{H}_{2} \mathrm{O}$ / acetonitrile (b) of different $f_{w} s$, as well as TPE-GA(r)-G1 in $\mathrm{H}_{2} \mathrm{O} /$ $\mathrm{MeOH}$ (c) and $\mathrm{H}_{2} \mathrm{O} /$ acetonitrile (d) of different $\mathrm{f}_{\mathrm{ws}} .20^{\circ} \mathrm{C}, \mathrm{C}=0.2 \mathrm{mg} \cdot \mathrm{mL}^{-1}$.

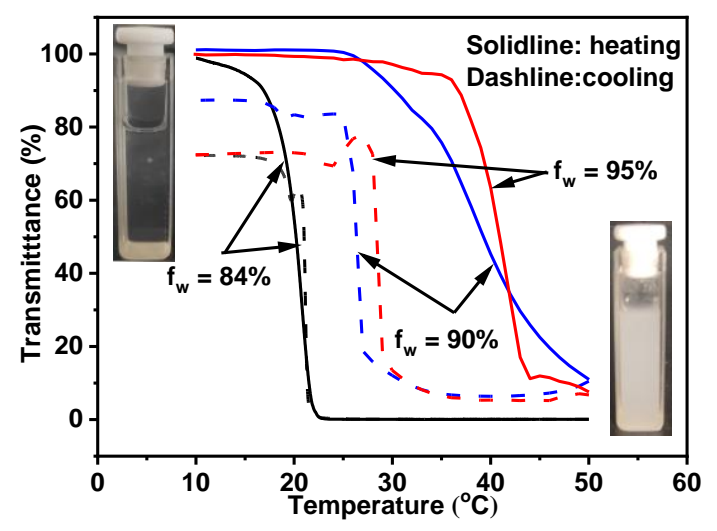

Figure S26. Plots of transmittance versus temperature for TPE-GA(r)-G1. $\mathrm{C}=0.5 \mathrm{mg} \cdot \mathrm{mL}^{-1} \cdot \lambda=700 \mathrm{~nm}$, heating rate $=0.2^{\circ} \mathrm{C} \cdot \mathrm{min}^{-1}$ 

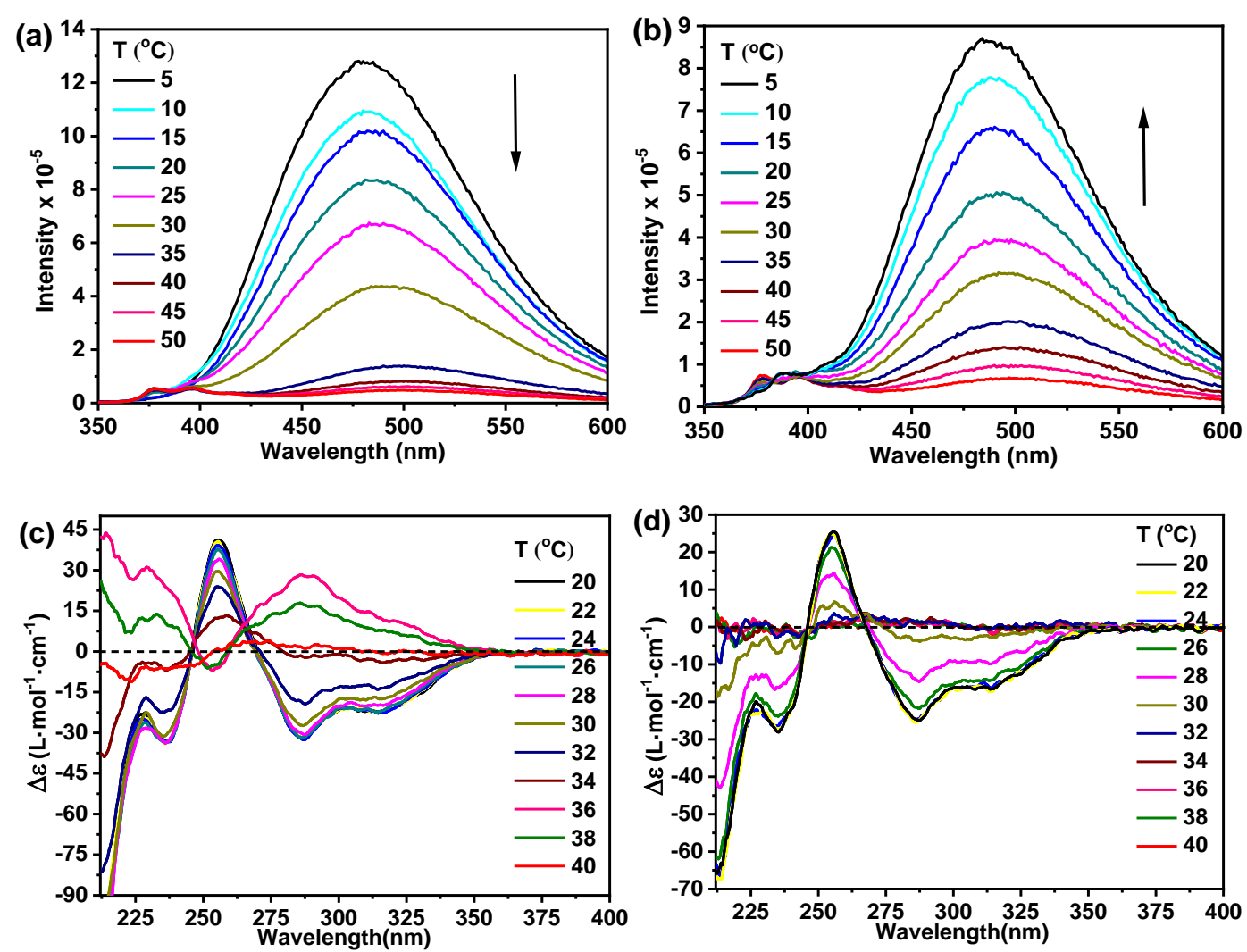

Figure S27. Fluorescence (FL) spectra of TPE-GA-G1 in $\mathrm{H}_{2} \mathrm{O} / \mathrm{THF}$ excited at $312 \mathrm{~nm}$ with increase (a) and decrease (b) of temperatures, as well as the CD spectra with increasing (c) and decrease (d) of temperature. $\mathrm{f}_{\mathrm{w}}=90 \%, \mathrm{c}=0.2 \mathrm{mg} \cdot \mathrm{mL}^{-1}$.
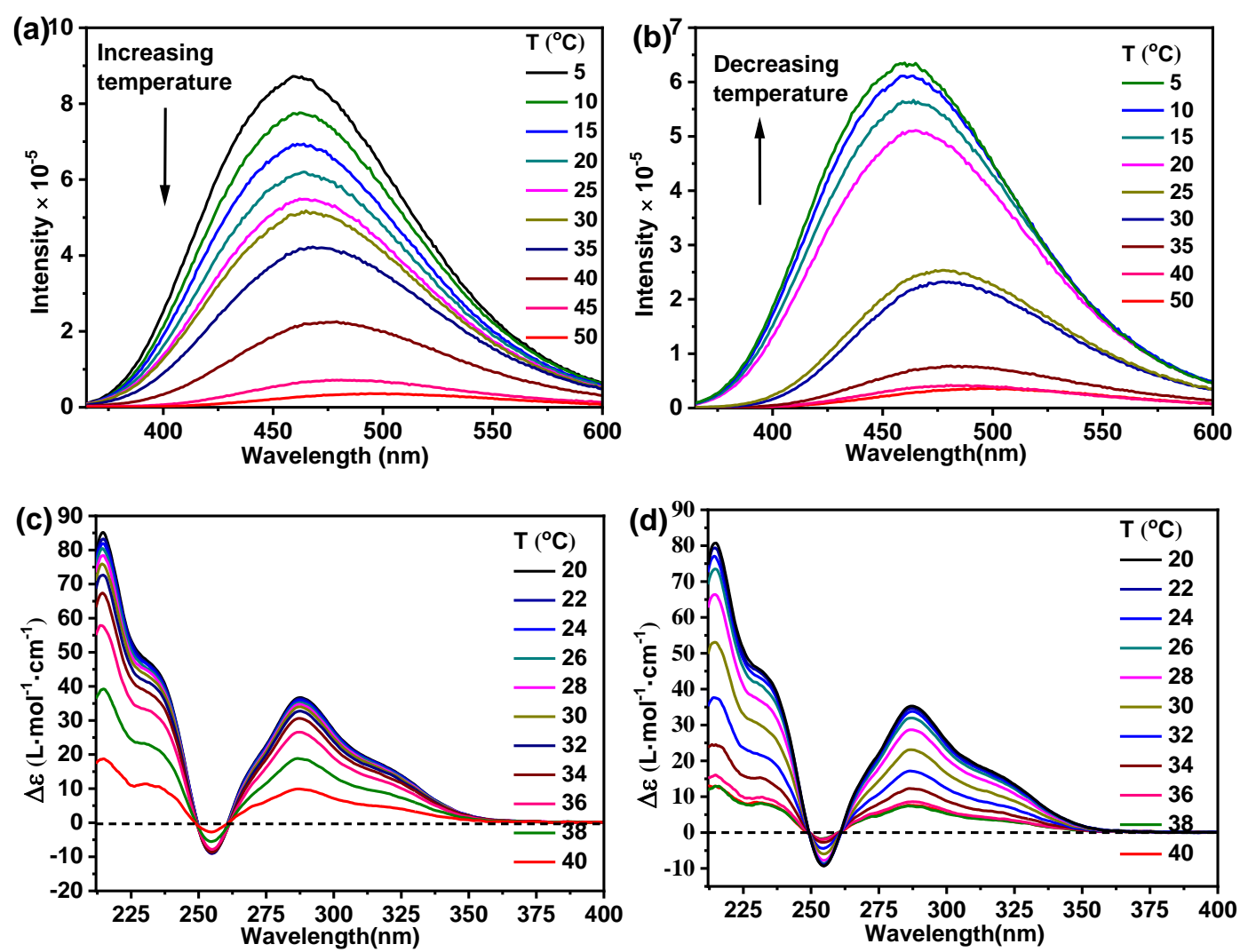

Figure S28. Fluorescence (FL) spectra of TPE-GA-G1 in $\mathrm{H}_{2} \mathrm{O} / \mathrm{THF}$ excited at $312 \mathrm{~nm}$ with increase (a) and decrease (b) of temperatures, 
as well as the CD spectra with increasing (c) and decrease (d) of temperature. $f_{w}=95 \%, c=0.2 \mathrm{mg} \cdot \mathrm{mL}^{-1}$.

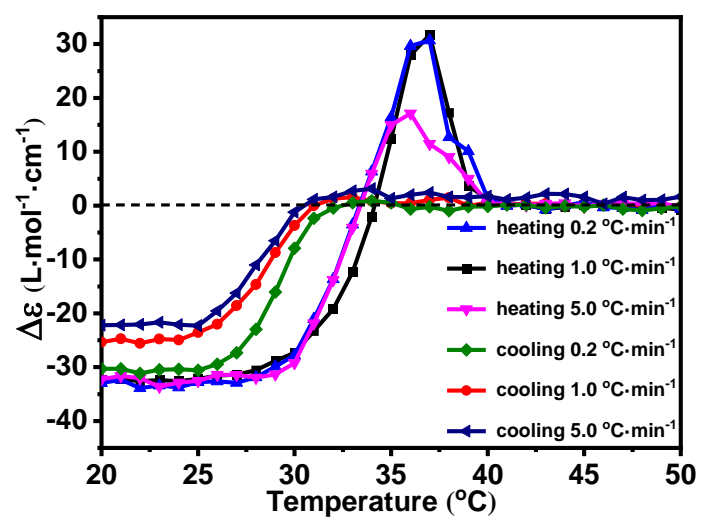

Figure S29. Cotton effect at $287 \mathrm{~nm}$ of TPE-GA-G1 in mixture of $\mathrm{H}_{2} \mathrm{O} / \mathrm{THF}$ with different heating rate. $\mathrm{c}=0.2 \mathrm{mg} \cdot \mathrm{mL}^{-1}, \mathrm{f}_{\mathrm{w}}=90 \%$.
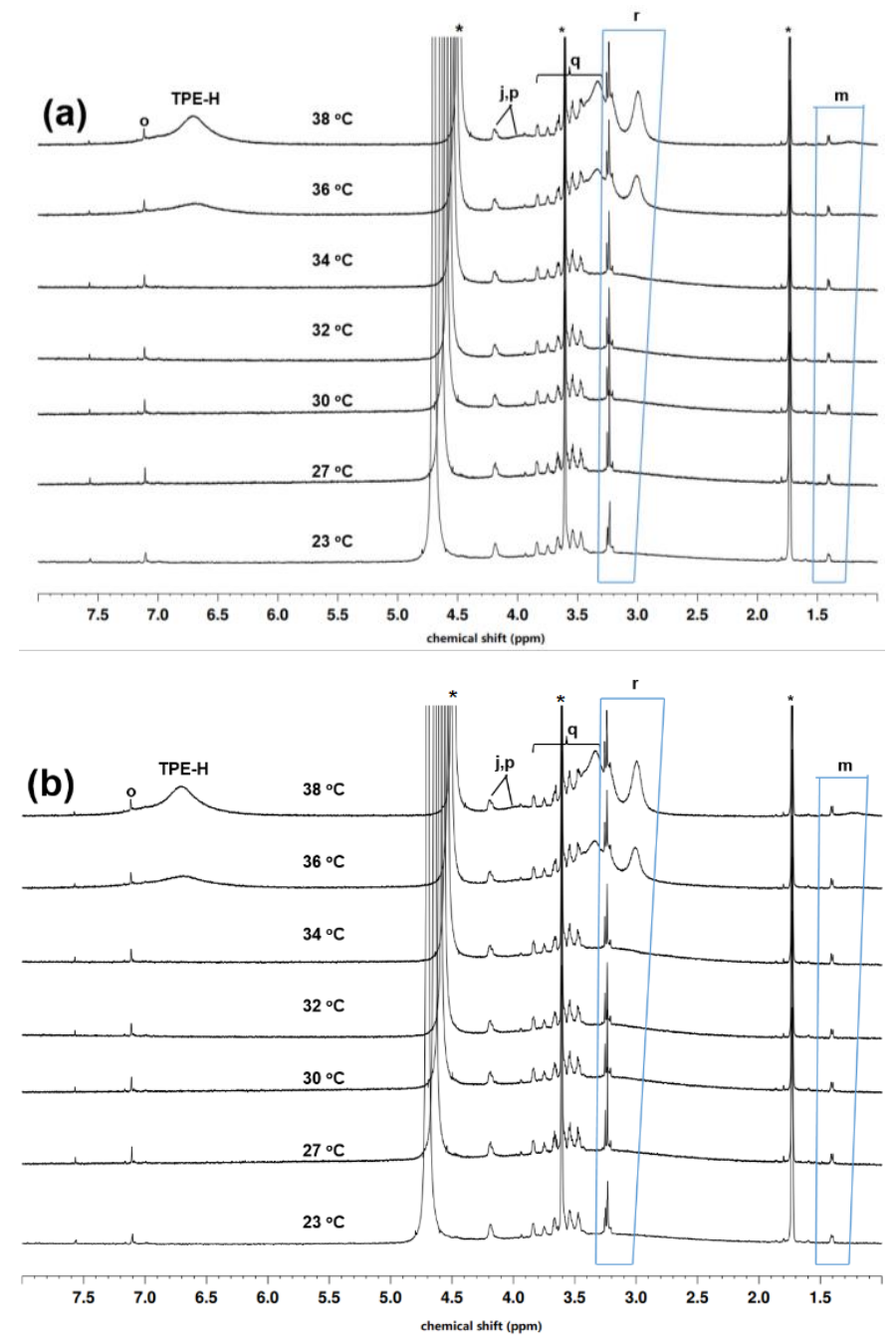

Figure S30. ${ }^{1} \mathrm{H}$ NMR spectra of TPE-GA-G1 in mixture of THF- $d_{8} / D_{2} \mathrm{O}$ at different temperatures: (a) $f_{w}=84 \%,(b) f_{w}=95 \% . c=5.0$ $\mathrm{mg} \cdot \mathrm{mL}^{-1}$. For proton assignments, please refer to Figure $2 \mathrm{c}$. 